\title{
Dimension of Experience: Metadiscourse in the Texts of Novice Non-Native, Novice Native and Expert Native Speaker
}

\author{
H. Gülru Yüksel*, Suzan Kavanoz
}

Faculty of Education, Ylldız Technical University 34210 Esenler-Istanbul-TURKEY

Corresponding Author: H. Gülru Yüksel, E-mail: hayuksel@yildiz.edu.tr

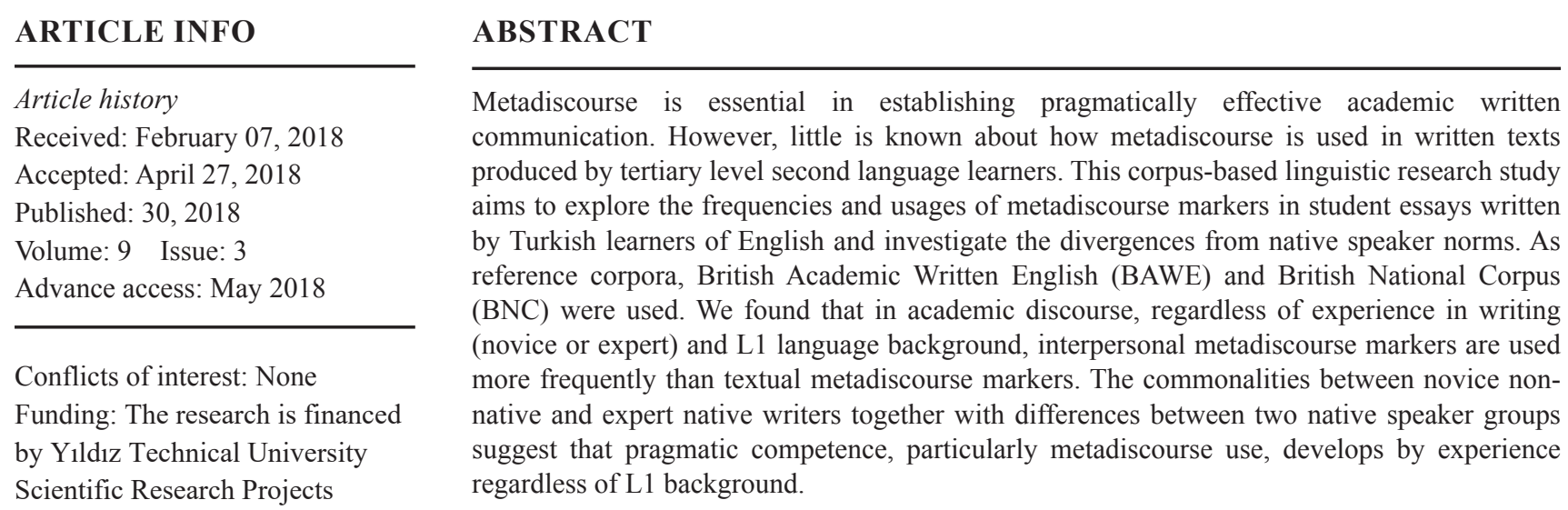

Coordination Office. No.

2012-09-02-KAP01

Key words: Academic writing, Native speaker writers, Corpus-linguistics, Metadiscourse, Novice learner writers

\section{INTRODUCATION}

The growing importance of English-medium instruction in education, and the upsurge in the number of programs offered in English in universities worldwide has increased the need for learners of English to develop effective communication skills that go beyond the level of accuracy. This demand has urged language educators and researchers to re-consider the teaching and learning of academic communication skills within second and foreign language (FL) contexts. Owing to the importance of language proficiency for success at tertiary level, researchers have been keenly interested in examining the development of written communication skills of non-native speakers of English from a variety of perspectives such as lexical richness (e.g. Laufer \& Nation, 1995), grammatical complexity (e.g., Biber, Gray \& Poonpon, 2011) and argument structure (e.g., Zare-Ee \& Farvardin, 2009). Despite the abundance of these studies, we still know little about how undergraduate second language (L2) writers communicate their meanings, and more importantly how they project themselves into their discourse while producing academic texts. An important linguistic resource to gain a deeper understanding of how L2 learners build reader-writer relation is to investigate the use of metadiscourse markers (henceforth, MDMs) in learner texts.
Metadiscourse markers (MDMs) are defined as "linguistic devices that are used to organize discourse or the writer's stance towards either its content or the reader" (Hyland, 2000.: 109). These linguistic features have been investigated in a number of contexts ranging from textbooks (Crismore, 1984) to research and newspaper articles (Hyland, 2000; Dafouz-Milne, 2008) from cross-cultural (Ädel, 2006) and cross-disciplinary (Hyland, 2004) perspectives. Much of this research has been conducted on academic writing produced either by postgraduate students, academicians, or professionals while undergraduate writing has received less attention. We still know little about how metadiscourse markers are used by undergraduate L 2 writers. From a pedagogical perspective, knowing how L2 learners' use deviates from native speaker norms is essential in order to design pedagogically effective materials and appropriately address learner needs in written communication. With this in mind, this paper investigates MDM usage compared to L1 learner counterparts and L1 expert writers. L2 learner texts are no less important than professional texts in terms of the significance in language acquisition and writing development. A comparison of metadiscourse in learner texts from different L1 backgrounds -namely Turkish and English- with different writing experi- 
ences -novice and expert- may reveal interesting commonalities and divergences in language use. Thus, in this study, we explored the frequencies and usages of MDMs in student essays written by Turkish learners of English who are considered as novice non-native writers (nov-NNS) in academic writing and investigate the divergences from native speaker norms by comparing the usages with two kinds of native speaker writers; namely, novice native speaker (nov-NS) and expert native speaker (exp-NS). The study seeks to answer the following research questions:

1. What is the incidence of frequency of textual and interpersonal MDMs used by novice non-native, novice native and expert native writers in English texts?

2. What are the similarities and differences in the distribution patterns of the use of metadiscourse markers between groups as evidenced in the corpora?

\section{LITERATURE REVIEW}

Metadiscourse has already been established as one of the essential elements of pragmatically effective academic written communication. Considering writing as a social act of engagement rather than a simple conveyance of information, Vande Kopple (1985: 83) defines metadiscourse as "discourse that people use not to expand referential material, but to help the readers connect, organize, interpret, evaluate, and develop attitudes towards that material". Along the same line of thought, Hyland (2004: 133) regards metadiscourse as a cover term for "self-reflective linguistic expressions referring to the evolving text, to the writer, and to the imagined readers of that text".

To date, various classifications of metadiscourse markers have been proposed (e.g. Ädel, 2006; Crismore, Markkanen \& Steffensen, 1993; Vande Kopple, 1985). Among these taxonomies, one of the most cited frameworks was proposed by Crismore et al. (1993). Following Halliday's macro-functions of text and modifying Vande Kopple's system of classification, Crismore and his colleagues (1993) grouped metadiscourse under two main categories as textual and interpersonal. While the former enables the writer "to relate and connect bits of ideational material within a text and helps the text make sense in a particular situation for readers", the later "allows us to reveal our personalities, to evaluate and react to the ideational material" (Vande Kopple, 1985: 86). In the model, the textual and interpersonal categories are further classified into more specific functions. Later, in order to reduce functional overlapping, the model was re-modified by Hyland (1998) and Hyland and Tse (2004) by keeping the main categorical labels and eliminating sub-categories. In the present study, this re-modified model is used for analysis. Due to space constraints, instead of the complete list of MDMs that were identified in the data, major categories, their functions and a few exemplars are presented in Table 1 below.

The usage and function of MDMs have so far been investigated from a variety of perspectives including cross-linguistic, cross-cultural (Dahl, 2004; Dafouz-Milne, 2008), cross-disciplinary (Hyland \& Tse, 2004; Lin \& Evans, 2012) and across genres (Fu \& Hyland, 2014). For example, in her comparative study Dahl (2004) explored writers' manifestation of themselves in three languages (English, French and Norwegian), and three disciplines (Economics, Linguistics and Medicine). She found that in Economics and Linguistics, English and Norwegian researchers use more metadiscourse than their French counterparts. However, within the field of Medicine, texts published in all three languages display a uniform pattern demonstrating little use of metadiscourse. In another study, Dafouz-Milne (2008) investigated the use of textual and interpersonal markers in Spanish and English newspaper columns. The findings suggested that although both textual and interpersonal MDMs are present in English and Spanish newspaper columns, distributional variations exist in certain categories. Variety in the use of metadiscourse has also been noted in studies comparing different genres. For instance, comparing popular science and opinion texts, Fu and Hyland (2014) explored how authors engage with their readers. They reported that despite the similarity in audience and sources, authors structure their interactions very differently. One remarkable implication of these comparative studies is that the use of metadiscourse is not uniform across languages, disciplines and genres, lending support to the claim that while constructing texts, writers

Table 1. Categories and functions of metadiscourse in academic texts

\begin{tabular}{lll}
\hline Category & Function & Examples \\
\hline $\begin{array}{l}\text { Textual metadiscourse } \\
\text { Logical connectives }\end{array}$ & Express semantic relations between main clauses & In addition, but, etc. \\
Frame markers & Refer to discourse acts or text stages in an explicit way & Finally, our aim, etc. \\
Code glosses & Help readers grasp meanings of ideational material & Namely, such as, etc. \\
Endophoric markers & Refer to information in other parts of the text & In section X, etc. \\
Evidentials & Refer to source of information from other texts & According to X, etc. \\
Interpersonal metadiscourse & & Might, perhaps, etc. \\
Hedges & Withhold writer's full commitment to statements & In fact, definitely, etc. \\
Emphatics & Emphasize force or writer's certainty & Unfortunately, etc. \\
Attitude markers & Express writer's attitude to proposition & Frankly, note that, etc. \\
Relation markers & Explicitly refer to or build relationship with reader & I, we, my, etc. \\
Person markers & Explicit reference to author &
\end{tabular}


employ varying MDMs depending on the social and cultural contexts.

Within academic context MDMs have been investigated both individually and comparatively in research articles, textbooks and dissertations (Hyland, 1994; Kuhi \& Behnam, 2011; Kawase, 2015). In one of the earlier studies, Hyland (1994) investigated the use of hedging devices in a range of EAP and ESP textbooks and found that more emphasis is placed on this issue in EAP textbooks. Later, Kuhi and Benham (2011) compared the use of metadiscourse in research articles, handbook chapters, textbook chapters and introductory textbooks produced in the field of applied linguistics found marked variations in use. Similarly, in a more recent study comparing the use of metadiscourse in article introductions and $\mathrm{PhD}$ thesis introductions written in the same field, Kawase (2015) reported that metadiscourse is used more frequently in article introductions. Such studies have contributed a great deal to our understanding of how writers employ MDMs in varying degrees from one genre to another.

Despite the extensive interest on metadiscourse in professional academic genres, research focusing on the texts produced by undergraduate learners is still limited in number. In one of the earlier studies Crismore and his colleagues (1993) investigated the cultural variations in persuasive texts written by American and Finnish university students and found that although students in both countries used all categories and subcategories, Finnish students used more metadiscourse markers. Later, Hyland and Milton (1997) compared the expressions of doubt and certainty in the exam papers of Cantonese learners with British counterparts. The study revealed significant differences between groups, with L2 writers depending on a rather limited range of items, making bold comments and demonstrating greater problems in expressing certainty. In her comparative study, Ädel (2006) investigated the use of MDMs in argumentative texts written by advanced L2 learners of English and by native Anglo-American English learners. She also found marked differences between L1 and L2 learners' texts in terms of metadiscourse use, particularly in the use of personal metadiscourse markers. In another study, exploring use of metadiscourse in final year undergraduate students' research reports, Letsoela (2013) found that students show a greater preference for the use of textual metadiscourse rather than interpersonal metadiscourse. Similar results were obtained by Rustipa (2014) who examined the use of MDMs in 7 Indonesian EFL learners' persuasive writings in comparison to extracts from BAWE corpus using the classification of Hyland and Tse (2004). She reported that while the occurrences of textual markers in learner texts are overall closely similar to those considered as standard proficient writing, the occurrences of hedges, boosters and engagement markers are different from the standard proficient writing. These studies demonstrate that L2 learner writers are more prone to employ textual than interpersonal MDMs, and that their use deviates from proficient writing norms.

Compared to the international context, studies evaluating the use of MDMs by Turkish speakers of English are relatively few in number (Akbaş, 2012; Bayyurt, 2010; Bayyurt \& Akbaş, 2014; Konca \& Nasiri, 2014). What is more, to the best of our knowledge, there is scant attention on the use of MDMs in undergraduate L2 learners' texts (Can, 2006, 2012; Çandarl1, Bayyurt, \& Mart1, 2015; Uysal, 2012). In his M.A. dissertation, Can (2006) compared the use of MDMs in essays written by Turkish monolingual, Turkish bilingual and American monolingual university students. He found that monolingual American students use logical connectives, frame markers, code glosses, and first person singular markers more frequently than the other two groups. In his recent study Can (2012) investigated use of stance adverbs by intermediate level of English in Turkish International Corpus of Learner English (TICLE) and compared to the ones in LOCNESS parallel corpus to find out the similarities and differences. His results revealed that Turkish learners of English use a fewer variety of stance adverbs more frequently than American learner writers. In another study, Çandarlı and her colleagues (2015) compared the use of authorial presence markers in Turkish and English essays written by Turkish students with advanced level of English, and English essays written by monolingual American students. Their results indicated that the use of authorial presence markers in English essays by Turkish students was more similar to that of novice native English speaking students. The findings of these studies suggest presence of divergence from native speaker norms.

All the abovementioned studies compared second language learner writing with either British or American learner writing with the claim that these two groups of subjects matched in age and educational experience. However, we argue that composing pragmatically effective writings requires experience and a long-term exposure to the sample texts with the demanded qualities. Furthermore, for L2 learners the frequency of exposure may also influence their choices. Nevertheless, in most foreign language learning settings, learners are not exposed to foreign language under natural conditions, but rather learn the target language through texts written by expert writers of English who could be non-native speakers as well. In addition, the rate and duration of their exposure is comparatively less than their L1 speaker counterparts.

\section{METHOD}

This is a corpus-based linguistic research study seeking both the similarities and differences among nov-NNS, nov-NS and exp-NS writers with respect to the use of MDMs. Data for the research came from a 2-year university funded research project investigating MDMs used by undergraduate adult learners with intermediate level of English. Data from Turkish nov-NNS were collected throughout one semester in Written Communication class. In addition to nov-NNS corpus, in order to compare MDM use among non-native and native writer groups, two corpora were used as reference tools (BAWE for nov-NS and BNC for exp-NS). The following section describes the three corpora used and the procedures followed for data collection and analysis.

\section{Corpora and Procedures}

In the study, a novice non-native learner corpus was compiled by the researchers and two native corpora were used as reference native speaker corpora. 


\section{Novice Non-Native Learner Corpus}

For the purpose of this study a non-native learner corpus, Yıldız Learner Writer Corpus (henceforth, YLW), was compiled by the researchers. The compilation was initiated in 2013-2014 academic year. The corpus comprised of essays written by Turkish learners of English. The corpus design features are given in Table 2.

All of the participants were second year undergraduate students enrolled in English Language Teaching program at a state university in Turkey. They had to demonstrate a B2 level of English by passing the university's English proficiency test before enrolling in their program. They had already taken Advanced Reading and Writing I-II courses for two semesters in the first year of the program in which they were introduced to the basic conventions of writing starting from formulation of thesis statement to composing fulllength college essays. However, in the second year they have to take Written Communication course that focuses on the development of the knowledge and skills necessary for effective written communication. During corpus compilation, the students were asked to write five different types of essays throughout the semester. All students were given the same topic and same class time to finalize their writing tasks. The instructor informed the students that their essays could be used for research purposes without revealing their identities and requested their permission. Only the essays whose writers gave written consent were included in the corpus. The YLW corpus held 316 pieces of student essays, ranging in length from 400 words to 750 words. Essays were cleaned up by removing titles and numbers to ensure these features did not interfere with the concordance analysis. The YLW corpus was analysed using Concordance 3.3 program in order to find the occurrences of MDMs.

\section{Reference Native Speaker Corpora}

British Academic Written English (BAWE) and British National Corpus (BNC) were used as reference corpora. For both corpora, query was done via the Sketch Engine, a corpus-processing tool that enables researchers see a concordance for any word, phrase or grammatical construction in one of the corpora provided, and allows users to narrow down search through a three-level filter: query type, con- text and text type (more information can be found at https:// www.sketchengine.co.uk/user-guide/).

The BAWE corpus was compiled in collaboration with the Universities of Warwick, Reading and Oxford Brookes. As a whole, it holds 2761 pieces of proficient assessed student writings, ranging in length from about 500 words to about 5000 words, distributed across four broad disciplinary areas (Arts and Humanities, Social Sciences, Life Sciences and Physical Sciences) and across four levels of study (undergraduate and taught masters level). Instead of using the whole BAWE corpus data, in order to have data sets comparable to our non-native learner corpus, we narrowed down the query using the Sketch Engine tool. Table 3 displays the BAWE corpus query limitation criterion.

As an expert reference native writer corpus, we preferred using British National Corpus (BNC) which is a 100-million-word collection of samples of written $(90 \%)$ and spoken $(10 \%)$ language from a wide range of sources, designed to represent a wide cross-section of British English. A similar procedure was followed with the BNC corpus, and the query was limited. Table 4 displays the BNC corpus query limitation criterion.

\section{Data Analysis}

For the present study, we excluded endophoric markers and evidentials from the analysis since the learner corpus consisted only of short student essays in which reference either to information in other parts of the text or to source of information is hardly seen. During raw frequency analysis, the searched words were not assigned to particular categories on a priori basis, but rather, judgements as to the correct categorization for each word was made by looking at the text of each individual concordance line. Although it was incredibly time-consuming, the procedure was preferred in order to ensure a higher degree of accuracy. Since the three corpora were of different sizes, in order to compare occurrence frequency counts across corpora, the raw frequencies were normalized using the formula: $f=$ raw occurrence/word token count $x$ 1000. As a final step, data was manually checked for similarities and/or differences within categories, as well as among writer groups, that appeared significant. In order to calculate statistical differences among the three corpora

Table 2. Yildiz learner writer (YLW) corpus

\begin{tabular}{lll}
\hline Design features & & \\
\hline Learner features & L1 & Turkish \\
& Language level & Intermediate \\
Linguistic features & Educational level & Undergraduate (1-4 years) \\
& Mode & Written \\
Textual features & Genre & Essay \\
& Disciplinary area & Applied linguistics \\
& Texts & 316 \\
& Style & Argumentative, cause-effect, opinion, comparison-contrast \\
\hline
\end{tabular}


(YLW vs. BAWE; YLW vs. BNC; and BAWE vs. BNC), Chi-square test, a non-parametric test which makes no assumption of normality, was performed. The significance level was established at $\mathrm{p}<0.05$.

\section{RESULTS AND DISCUSSION}

Following the main metadiscourse marker categories, the findings will be presented under three headings: overall metadiscourse, textual metadiscourse and interpersonal metadiscourse.

\section{Overall findings}

The overall frequency counts show that one in 6 words in YLW, one in 11 words in BAWE and one in 8 words in BNC is a metadiscourse marker. If one considers language used by expert writers as the norm, this result indicates that not only non-native but also native learner writers demonstrate divergence from the norm. (Table 5).

As for the main categories, the occurrence of interpersonal metadiscourse was more frequent in all three corpora. This

Table 3. BAWE corpus query limitation criterion

\begin{tabular}{lll}
\hline Limitation criterion & \\
\hline Learner features & L1 & English \\
& Grade & $\begin{array}{l}\text { Undergraduate } \\
(1-2 \text { levels })\end{array}$ \\
Linguistic features & Medium & Written \\
& Text type & Essay \\
Textual features & Disciplinary area & Arts and Humanities \\
& Difficulty & Medium \\
& Texts & 484 \\
& Tokens & 1.051 .970 \\
\hline
\end{tabular}

Table 4. BNC corpus query limitation criterion

\begin{tabular}{lll}
\hline Limitation criterion & & \\
\hline Writer features & L1 & English; monolingual \\
Linguistic features & Medium & Written/published \\
& Text type & $\begin{array}{l}\text { Academic: book and } \\
\text { periodical } \\
\text { Textual features }\end{array}$ \\
& Domain & $\begin{array}{l}\text { Social Sciences; Arts and } \\
\text { Humanities }\end{array}$ \\
& & 229 \\
& Texts & 7.520 .539 \\
\hline
\end{tabular}

result is similar to other MDM studies (Heng \& Tan, 2010) whereby the frequency of use of the interpersonal MDM is higher compared to the textual MDM.

\section{Textual Metadiscourse}

Textual metadiscourse category includes linguistic resources that writers use to organize their texts, and to structure their propositions. In all three corpora, the most frequent sub-category was logical connectors, accounting for the highest proportion of total textual metadiscourse $(72.3 \%$ in YLW, $82.4 \%$ in BAWE and $75.6 \%$ in BNC) (see Fig. 1).

This finding is in line with the study by Akbaş (2012), which also found equal frequencies in logical connectors used by Turkish (L1) and English (L1) novice writers. Similar results have been reported in studies conducted in different contexts (Hyland, 2004; Letsoela, 2013; Ting \& Wharton, 2012; Tan \& Eng, 2014). Although this is considered as an overt indication of learners' attention to text coherence by previous researchers, the similar tendency that we observed in expert writer corpus, suggest novice writers' attempt to replicate the metadiscourse used in the textbooks produced by expert writers. Thus, contrary to suggestions of previous researchers we abstain from seeing this finding as an overt indication of learners' attention to text coherence.

The second most frequently used subcategory in YWL corpus was the frame markers category. Indeed, our non-native writers employed almost two times more frame markers $(15.2 \%)$ than novice and expert native writer groups $(6 \%$ in BAWE and $6.5 \%$ in BNC). As for the code glosses subcategory, a similar use by both novice writer groups (in YLW $12.6 \%$ and in BAWE $11.4 \%$ of total textual metadiscourse) was detected. Despite these differences in the proportions, the chi-square analysis revealed no statistically significant differences among groups in textual metadiscourse category.

When we examined in detail which MDMs were chosen by each writer group, certain variations were identified among groups. In code glosses category, the three most preferred forms were almost alike. In all corpora, forms with exemplification function - or X, such as and for examplewere the most frequent forms. However, except for these, the total number of the forms and the ranking orders varied among groups. In terms of the number of forms used, while non-native and native learner writers used a total of 20 different forms, expert writers used 23 different forms. As for the ranking order, for example, the form indeed was ranked the fourth in BNC, but it was ranked the seventh in BAWE and sixteenth in YLW. This variation in rank shows that the differences in number of MDM occurrences is further supported by

Table 5. Distribution of MDMs in three corpora (frequencies per 1000)

\begin{tabular}{|c|c|c|c|c|c|c|}
\hline \multirow[t]{2}{*}{ Category } & \multicolumn{2}{|c|}{ YLW } & \multicolumn{2}{|c|}{ BAWE } & \multicolumn{2}{|c|}{ BNC } \\
\hline & $f$ & $\%$ & $f$ & $\%$ & $f$ & $\%$ \\
\hline Textual & 68.04 & 43.82 & 35.95 & 39.59 & 57.22 & 47.40 \\
\hline Interpersonal & 87.24 & 56.18 & 54.86 & 60.41 & 63.51 & 52.60 \\
\hline Total & 155.27 & & 90.81 & & 120.74 & \\
\hline
\end{tabular}




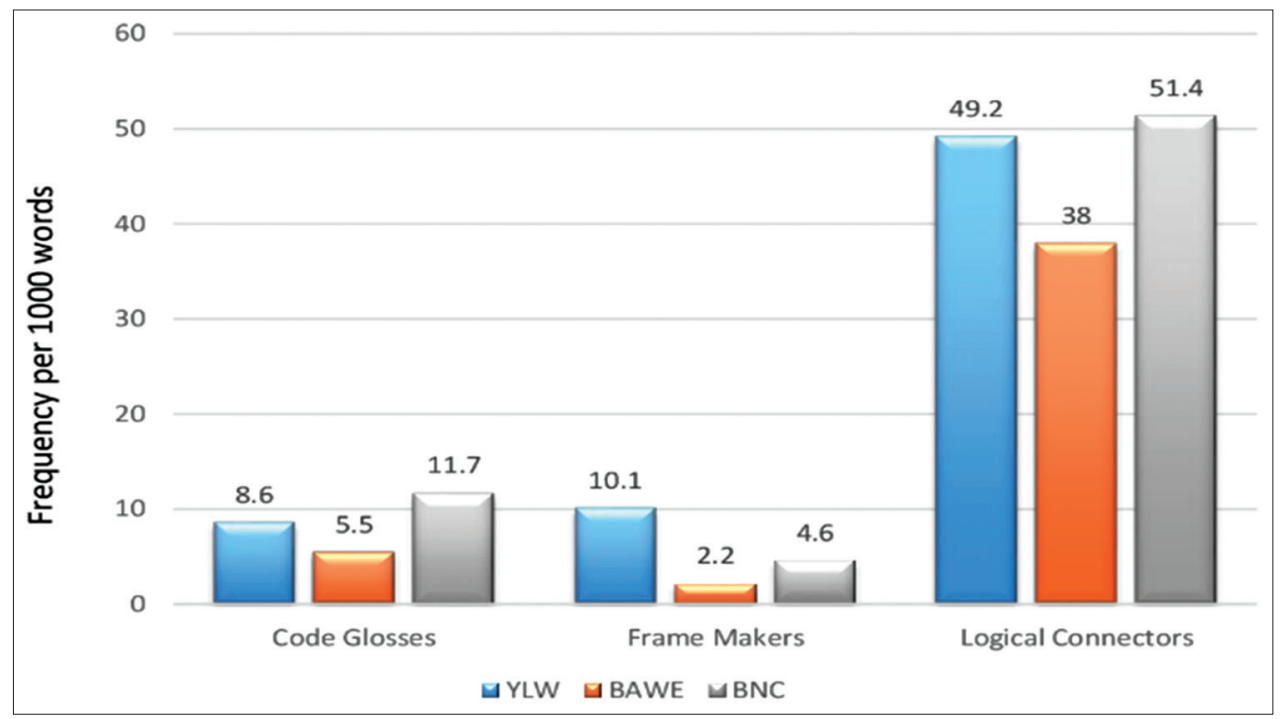

Figure 1. Textual metadiscourse sub-categories in three corpora

differences in their lexical selection of metadiscourse signals. Furthermore, forms with reformulation function were more frequent in BNC than in BAWE and YLW. In a similar vein, Aull and Lancaster (2014), in their study comparing the use of stance markers by first-year and advanced writers found that advanced writers use both categories of code glosses more frequently than the first-year writers. These findings indicate that while novice writers can properly support their propositions with examples, they experience problems in marking the important and complex foci of the text. As Rustipa (2014) claims the learner writers' problem in elaborating their messages might be due to their inexperience in predicting their readers' background knowledge.

The most noticeable differences were found in the frame markers category. While the MDMs for sequencing and labelling stages were similar in all three corpora, the MDMs that are used to announce goals and shift topic in YLW corpus were different from the two reference corpora. This difference indicates that non-native learner writers seem to have trouble in announcing goals and shifting topic. Our non-native writers' vocabulary was limited to the forms intend to and intention for expressing goals and they did not use forms other than so and now when it comes to changing the topic. Similarly, Heng and Tan (2010) reported a notable absence of frame marker forms that announce goals, such as objective, aim, purpose and those that denote a shift in topic, such as, back to, with regard to and turn to in their learner corpus.

Regarding logical connectives, the first three forms in all three corpora consisted of and, but and because. Despite similarities in the use of these simpler forms, different from novice non-native writers both native writer groups also used less frequent forms such as conversely, nonetheless, and in contrast. This suggests that learner writers may have a narrower repertoire of logical connectors, and may feel insecure in using such forms.

\section{Interpersonal Metadiscourse}

The markers in this category are used by the writers to manage the information flow, to encode an interaction and build a relationship with the reader. Findings in interpersonal metadiscourse category displayed a different pattern with respect to distribution of the sub-categories. Both similarities and differences were observed among three writer groups. One notable similarity was that the most frequently employed sub-categories were the same in all three corpora. Regardless of experience and L1 background relation markers appeared to be the most frequently utilized subcategory comprising $35.2 \%$ in YLW, 33.5\% in BAWE and 36.7\% in BNC of all interpersonal uses. Similarly, Heng and Tan (2010) reported a high frequency of relation marker use by second language learners. Although attitude markers was the least frequently occurring sub-category in all three corpora, its occurrence in YLW was two times less frequent $(2.1 \%$ of intertextual metadiscourse) than both reference corpora (5.5\% in BAWE and 4.6\% in BNC). The low occurrence of attitude markers is similarly found by Letsoela (2013) and Tan and Eng (2014). In the Turkish context however, contradictory findings have been documented. While Çandarlı et al. (2015) collecting data from advanced learners of English reported that the number of different attitude markers employed by American and Turkish students was similar, Can (2012) argued that the variety of attitude markers in Turkish students' English essays was far lower than that in American students' essays. This may be resulting from the learners' language proficiency. In our case, similar to the study by Can (2012), our learners might have developed an avoidance strategy due to their limited lexical competence. Figure 2.

In the use of hedges, emphatics and person markers, the YLW corpus diverged from the two native speaker corpora. The most salient divergence was observed in the person markers sub-category. The proportion of this subcategory in the YLW corpus $(32.4 \%)$ was almost two times more than the nov-NS corpus (14.9\% in BAWE) and three times more than the exp-native writer corpus (11.8\% in BNC). Conversely, a reversed pattern was seen in the hedges category. While hedges comprise $16.8 \%$ of the total interpersonal metadiscourse in the YLW corpus, they were almost two 


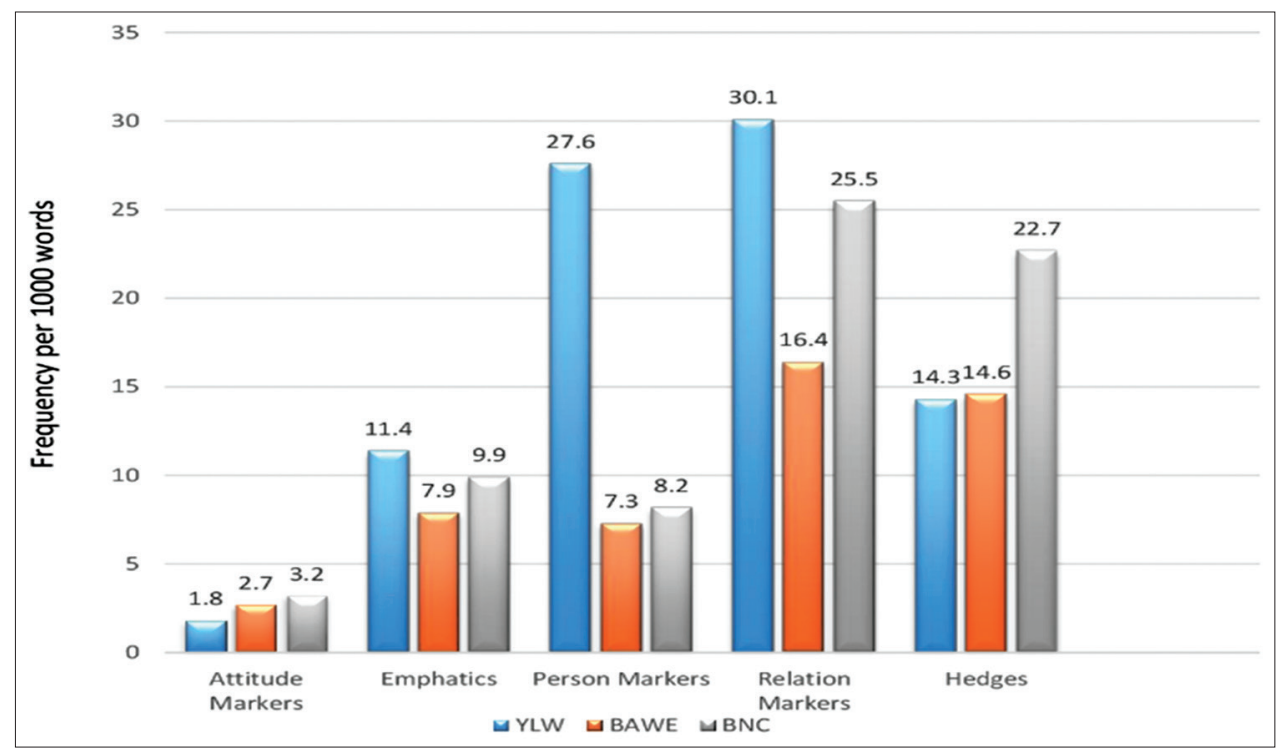

Figure 2. Interpersonal metadiscourse sub-categories in three corpora

times more frequent in the BNC accounting for $32.7 \%$ of the total interpersonal metadiscourse. This suggests that while expert writers abstain from making overstatements, novice non-native learners opt for expressing their commitment to their propositions more. With regards to emphatics, despite the difference seen in the rank of occurrence between non-native and native writer groups, in terms of proportions all three corpora displayed a similar picture $(13.4 \%$ in YLW, $14.9 \%$ in BAWE and $14.2 \%$ in BNC).

The chi-square between groups analysis revealed statistically significant differences among interpersonal metadiscourse sub-categories. Between the YLW and BAWE, we found statistically significant differences in the use of relation markers $(p=0.018)$ and person markers $(p=0.004)$. Compared to nov-NS writer corpus (BAWE), person makers were more frequent, yet relation markers were less frequent in the nov-NNS corpus (YLW). The nov-NNS and exp-NS corpora comparison also yielded statistically significant differences in the use of person markers $(p=0.001)$ and hedges $(p=0.028)$ showing non-native learners' tendency to use more person markers and fewer hedges than expert native writers.

In the use of emphatics and attitude markers, similarity in proportions among groups suggest that both novice learner writer groups and expert native writer group have an inclination to express certainty in their messages and voice their attitudes to the propositional content at resembling levels. Nonetheless, in terms of variety of forms, we observed differences between L1 and L2 writer groups. Total number of emphatics used by both learner writer groups (a total of 32 forms in YLW and 37 forms in BAWE) was comparatively lower than total number of emphatics used by expert writer group (a total of 39 forms in BNC). Regarding attitude markers, despite similarity in proportions, forms used by the three writer groups displayed variations. Even though non-native learners expressed their attitude using fewer number of forms such as important and essential most of the time (36 different forms were detected in YLW), both native writer groups prefer to use a variety of forms for communicating their attitudes (in BAWE 55 different forms and in BNC 57 different forms were used). These results conform to the findings of earlier studies conducted with Chinese, Japanese and Korean learners of English, which revealed that foreign language learners rely on a more limited lexical range of emphatics and attitude markers (Can, 2012; Hinkel, 2003; Hyland \& Milton 1997).

With regards to person markers, the high percentage of occurrence in the YLW corpus is an explicit sign of overuse. In this category, the most frequently used person marker form is the first person pronoun I. In fact, in the non-native corpus the occurrence of this form is four times more than that of both native speaker corpora. Turkish writers sound highly individualistic in their writings and thus more inclined to express a direct authorial persona. Interestingly, in terms of the use of person markers, our finding contrasts with the findings of previous studies from the same context (Çandarlı et. al., 2015). This might be due to the language proficiency levels of the writers and their insufficient experience in writing academic texts. Because unlike the non-native learners in our study, in the study conducted by Çandarlı et al. (2015), the participants had an advanced level of proficiency.

As for relation markers, although this subcategory constitutes the most frequently employed interpersonal markers in all three corpora, a comparatively lower percentage of occurrence is observed in non-native learner corpus. A total of 66 different forms were employed by non-native learner writers while the number of different forms employed by native speaker learners and expert writers were 70 and 71, respectively. Unlike the expert writer groups, the second person pronoun is among the three most preferred forms for both learner writer groups. The expert writer group, on the other hand, focuses their attention more on facts by using verb+ forms. The high frequent use of second person pronoun in learner writing was also reported by Tan and Eng (2014). The researchers noted that Malaysian undergraduates try to be sensitive in creating a dialogic space with their readers by frequent use of second person pronoun; yet, this frequent use also makes the learners' writing seem more direct. Simi- 
lar results were disclosed by Hyland and Milton (1997). The Chinese learners in their study also chose to link themselves overtly with their ideas rather than referring to the readers. From these two findings, we can infer that L2 learner writers are more likely to experience problems in establishing links with their readers.

When hedges used by the three groups of writers were examined in detail, the most prevalent forms in YLW corpus were about, may and would, while in BAWE and BNC the first three preferred forms were would, could and may. The frequent use of about in non-native learner corpus can be considered as a sign of uncertainty regarding the idea presented. In terms of variety, there was a noticeable difference among the groups. While expert writers used 77 different hedges, BAWE writers used a total of 72 different hedges, and YLW writers used 61 different hedges in their essays. Our data suggests that non-native learners seem to be incompetent in using modals to mitigate their statements. This finding does not corroborate with previous research indicating that L2 users prefer to hedge their statements to obscure their authorial identity (see Bayyurt, 2010; Letsoela, 2013). Notwithstanding, our findings give support to Hyland and Milton (1997) who reported that within the framework of second language context, L2 writers were found to use fewer hedges presenting stronger commitments that points to problems in their writings.

\section{CONCLUSION}

This study examined the use of metadiscourse markers in English essays written by Turkish learners of English, and investigated similarities and differences used by novice non-native and native speakers and expert native speaker writers. The present corpus-based study has yielded several findings that can be summarized as follows:

1. In academic discourse, regardless of experience in writing (novice or expert) and L1 language background, interpersonal metadiscourse markers are used more frequently than textual metadiscourse markers. The same tendency is observed with the novice Turkish writers of English with intermediate level of proficiency.

2. In the textual metadiscourse category, all three groups of writers seem to pay attention to clarity of meaning and this clarity was achieved through the use of logical connectors. However, a clear-cut divergence is observed in the use of frame markers and code glosses between NNS and NS writers. Being novice in academic writing genre, L2 learner writers mostly concern about text stages and experience difficulty in clarifying their statements and providing examples where needed unlike NS writers.

3. In the interpersonal metadiscourse category, certain communalities and divergences between novice non-native and native speaker writers were observed. The percentage distribution of attitude markers and emphatics in our novice non-native learner corpus is more akin to expert native speaker corpus. The most salient differences are observed in the use of person markers and hedges. While novice L2 writers tend to overuse person markers, they tend to underuse hedges. The high frequency of use of person markers by L2 learners and contradictory results obtained in past research from the same context may imply an overuse resulting from insufficient experience in writing academic texts.

From the above summarized findings, two main conclusions can be drawn. First, the commonalities between novice non-native and expert native writers together with differences between two native speaker groups both in the variety and proportions strengthen our argument that pragmatic competence, particularly metadiscourse use, develops by experience regardless of L1 background. The use of identical subcategories in all three corpora might be indicative of the learners' trials to replicate the forms they are exposed to in the textbooks while producing their own essays. The second conclusion derived from the findings obtained in interpersonal metadiscourse is that language learners basically experience problems in building relations with the reader. This might result from the fact that the primary audience for the students is their instructor. Lack of having a clear sense of a real reader might prevent them from connecting with the recipients through using interpersonal features. The differences observed in the variety of forms used by novice L2 writers point to a need for cultural-sensitive curricula and explicit pragmatic instructions in writing classrooms.

Finally, we acknowledge several potential limitations of this study. First, the learner corpus was relatively small in size and the texts were compiled from students enrolled in a single program. These may limit the generalizability of the results to all novice L2 writers. Given the nature of learner population, further research is needed to better understand how L2 learners from different majors use metadiscourse in written communication. A second limitation might be the reference learner corpus specifications. The research could be extended with parallel learner corpora whose linguistic and textual characteristics are controlled. In addition, to test the possibility of developmental nature of pragmatic competence, research monitoring the writing process of the same learners throughout a longitudinal study would be worthwhile.

\section{REFERENCES}

Ädel, A. (2006). Metadiscourse in L1 and L2 English (vol. 24). Amsterdam: John Benjamins Publishing.

Akbaş, E. (2012). Exploring metadiscourse in master's dissertation abstracts: Cultural and linguistic variations across postgraduate writers. International Journal of Applied Linguistics and English Literature, 1, 12-26.

Aull, L. L., \& Lancaster, Z. (2014). Linguistic markers of stance in early and advanced academic writing: A corpus-based comparison. Written Communication, 31(2), 151-183.

Bayyurt, Y. (2010). Hedging in L1 and L2 student writing: A case in Turkey. In: Kincses-Nagy, E. (Eds.), Proceedings of the 15th International Conference of Turkish Linguistics. Szeged University Press, Szeged, pp. 123-132.

Bayyurt, Y., \& Akbaş, E. (2014). Akademik metinlerde kaçınma ve vurgulayıcı ifadelerin lisansüstü öğrenciler tarafindan algılanması ve kullanılması [Graduate 
students' perception and use of hedges and boosters in academic texts]. Ulusal Dilbilim Kurultayı Bildirileri. Hacettepe Üniversitesi Yayınları, Ankara, pp. 72-79.

Biber, D., Gray, B., \& Poonpon, K. (2011). Should we use characteristics of conversation to measure grammatical complexity in L2 writing development? TESOL Quarterly, 45(1), 5-35.

Can, C. (2006). An analysis of freshman year university students' argumentative essays. Unpublished MA thesis, Boğaziçi University, Istanbul.

Can, C. (2012). Uluslararası Türk öğrenici İngilizcesi derleminde tutum belirteçleri [Authorial Stance in Turkish International Corpus of Learner English]. Dilbilim Araştırmaları, 1, 39-53.

Crismore, A. (1984). The rhetoric of textbooks: Metadiscourse. Journal of Curriculum Studies, 16(3), 279-296.

Crismore, A., Markkanen, R., \& Steffensen, M. (1993). Metadiscourse in persuasive writing: A study of texts written by American and Finnish university students. Written Communication, 10, 39-71.

Çandarlı, D., Bayyurt, Y., \& Martı, L. (2015). Authorial presence in L1 and L2 novice academic writing: Cross-linguistic and cross-cultural perspectives. Journal of English for Academic Purposes, 20, 192-202.

Dafouz-Milne, E. (2008). The pragmatic role of textual and interpersonal metadiscourse markers in the construction and attainment of persuasion: A cross-linguistic study of newspaper discourse. Journal of Pragmatics, 40(1), 95-113.

Dahl, T. (2004). Textual metadiscourse in research articles: a marker of national culture or of academic discipline? Journal of Pragmatics, 36(10), 1807-1825.

Fu, X., \& Hyland, K. (2014). Interaction in two journalistic genres: A study of interactional metadiscourse. English Text Construction, 7(1), 122-144.

Heng, C. S., \& Tan, H. (2010). Extracting and comparing the intricacies of metadiscourse of two written persuasive corpora. International Journal of Education and Development Using Information and Communication Technology, 6(3), 124-146.

Hinkel, E. (2003). Teaching Academic ESL Writing. New York: Routledge.

Hyland, K. (1994). Hedging in academic writing and EAF textbooks. English for Specific Purposes, 13(3), 239-256.

Hyland, K. (1998). Persuasion and context: The pragmatic of academic metadiscourse. Journal of Pragmatics, 30(4), 437-455.

Hyland, K. (2000). Hedges, boosters and lexical invisibility: Noticing modifiers in academic texts. Language Awareness, 9(4), 179-197.

Hyland, K. (2004). Disciplinary interactions: Metadiscourse in L2 postgraduate writing. Journal of Second Language Writing, 13(2), 133-151.
Hyland, K., \& Milton, J. (1997). Qualification and certainty in L1 and L2 students' writing, Journal of Second Language Writing, 6(2), 183-205.

Hyland, K., \& Tse, P. (2004). Metadiscourse in academic writing: A reappraisal. Applied Linguistics, 25(2), 156-177.

Kawase, T. (2015). Metadiscourse in the introductions of $\mathrm{PhD}$ theses and research articles. Journal of English for Academic Purposes, 20, 114-124.

Konca, M. Y., \& Nasiri, S. (2014). How to hedge in psychology discipline? A Cross-national study. Journal of American Science, 10(10), 1-5.

Kuhi, D., \& Behnam, B. 2011. Generic variations and metadiscourse use in the writing of applied linguists: A comparative study and preliminary framework. Written Communication, 28(1), 97-141.

Laufer, B., \& Nation, P. (1995). Vocabulary size and use: Lexical richness in L2 written production. Applied Linguistics, 16(3), 307-322.

Letsoela, P. M. (2013). Interacting with readers: Metadiscourse features in national university of Lesotho undergraduate students' academic writing. International Journal of Linguistics, 5(6), 138.

Lin, L., \& Evans, S. (2012). Structural patterns in empirical research articles: A cross-disciplinary study. English for Specific Purposes, 31(3), 150-160.

Rustipa, K. (2014). Metadiscourse in Indonesian EFL learners' persuasive texts: A case study at English department. International Journal of English Linguistics, 4(1), 44-52.

Tan, H., \& Eng, W. B. (2014). Metadiscourse use in the persuasive writing of Malaysian undergraduate students. English Language Teaching 7(7), 26-39.

Ting, L., \& Wharton, S. (2012). Metadiscourse repertoire of L1 Mandarin undergraduates writing in English: A cross-contextual, cross-disciplinary study. Journal of English for Academic Purposes, 11(4), 345-356.

Uysal, H. H. (2012). Argumentation across L1 and L2 writing: Exploring cultural influences and transfer issues. Vigo International Journal of Applied Linguistics, 9, 133-159.

Vande Kopple, W.J. (1985). Some Exploratory Discourse on Metadiscourse. College Composition and Communication, 36(1), 82-93.

Vande Kopple, W.J. (2002). From the dynamic style to the synoptic style in spectroscopic articles in the physical review: Beginnings and 1980. Written Communication, 19(2), 227-264.

Zare-ee, A., \& Taghi Farvardin, M. (2009). Comparison of university level EFL learners' linguistic and rhetorical patterns as reflected in their L1 and L2 writing. Novitas-ROYAL, 3(2), 143-155. 